\title{
Organizational features of innovative CAD implementation in existing production systems
}

\author{
Denis Vannusov ${ }^{1}$, Vladimir Dadonov ${ }^{2}$, Maria Tereshchenko ${ }^{3}$ \\ ${ }^{1}$ Lead engineer METROPOLIS Co. Ltd., Moscow; \\ ${ }^{2}$ Cand. Sc. (Eng.), Associate Professor of Bauman University, Moscow; \\ ${ }^{3}$ Student of EBM6-52B Bauman University, Moscow.
}

\begin{abstract}
In the article reviewed automatic systems and their life cycle. Analyzed phases of the CAD implementation into civil engineering companies with regard to the factors that suppress their integration. Detailed processes of human-computer interaction during the implementation of innovative CAD technologies. Analyzed the results of this interaction.

Keywords: automatic systems, CAD, innovations in civil engineering, human-computer interaction.
\end{abstract}

\section{Introduction}

The development of society, scientific and technological progress at each stage is based on the key factors that drive it. The 20th century has become a period when the production processes were intensively computerized. Traditional methods of production, based on manual or mechanized labor, began to be replaced in various sectors of the economy by innovative automated processes. This required the rapid development of such scientific and technical disciplines as system analysis, mathematical and simulation modeling, theory of automatic control, operation research and others. Although the active development of technologies for complex production process automatization took place in the second half of $\mathrm{XX}$ century, today opportunities for optimization, improvement of methods and techniques of product creation continue to develop rapidly. Increasingly, the leadership of our country declares the necessity of transition to "digital economy". In the approved " Development Strategy for the Information Society of the Russian Federation for 2017-2030" the following definition of digital economy is given: "Digital economy is economic activity, in which the key factor of production is data in digital form, processing of large volumes and the use of analysis results which, compared to traditional forms of management can significantly increase the efficiency of various types of production, technology, equipment, storage, sale, delivery of goods and services. Obviously, this interpretation contains a number of valuation judgments, including "traditional forms of management ..." or "significantly increase efficiency ...". The same remark can be applied to phrases like "big data volumes", however, in the field of information technologies there is indeed a well-established term "Big Data", widely used in foreign publications of IT-thematics [12,13,21,22].

\section{Methods}


In the case of Human Machine Interaction Systems (HMI), the concept of "efficiency" is also regulated. Human-machine (or human-computer) interaction is a multidisciplinary scientific direction, existing and developing in order to improve the methods of development, evaluation and implementation of interactive computer systems designed for human usage, as well as for the study of various aspects of this usage [1]. Based on this definition, we conclude that the HMI is inextricably linked with the features of computer systems, which include, for example, automated systems. An automated system is a system consisting of personnel and a set of automation tools for its activity that implements information technology to perform the established functions [15]. Efficiency of the automated systems (further AS) is regulated by GOST 34.003-90 and means property of AS, characterized by achievement degree of the goals set at its creation. For an estimation of achievement degree of the purposes, the customer forms indicators of efficiency on which basis estimation is made. Such indicators may be one or more. Some of them are: reducing the probability of errors, increasing productivity, improving the quality of the finished product, etc. It is obvious that all these indicators, to some extent, affect the efficiency of production and are the object of direct interest from the management of the enterprise.

There is a conditional classification of AS by type of activity:

- $\quad$ enterprise management systems (ERP);

- $\quad$ process control systems (ACS TP);

- $\quad$ electronic document management systems (DMS);

- $\quad$ computer-aided design (CAD) systems;

- $\quad$ other systems.

All these types of AS are either individually or comprehensively successfully implemented at modern enterprises. However, if we take into account the principles of HMI the key role here is certainly performed by CAD.

CAD is the organizational-technical system which is a part of the design organization (enterprise) and carrying out designing by means of a complex of means of the automated designing [16].

Autodesk AutoCAD CAD is the most popular today and is widely used by designers all over the world. And our country is not an exception here. Nevertheless, the tendency to switch to use of information modelling, causes a relevance of introduction in existing industrial process of the newest $\mathrm{CAD}$, allowing successfully to realise this problem. Introduction process is one of five phases of life cycle of AS (figure 1). Each of such phases corresponds to the specific (so-called phase) condition of system, predetermined by the period of a life, AS and the purposes facing the customer and the developer [2].

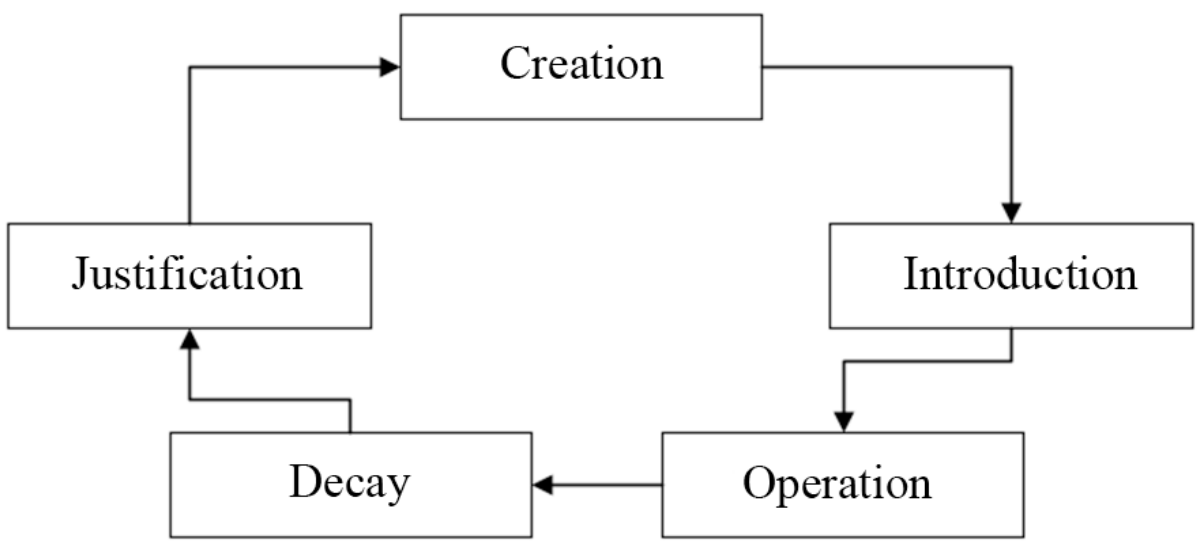

Fig. 1. AS life cycle, developed by the authors 
It is obvious that in the case of already existing CAD, the phases "justification" and "creation" lose their relevance. The "decay" phase is not considered, as at this stage we consider only such systems which will allow to raise efficiency of industrial process in the conditions of the set parameters of efficiency (the most innovative AS). Actually, interaction of the man (operator) and CAD is carried out at "introduction" and "operation" stages. It is necessary to notice that in practice these two phases can be combined as the operator solves industrial problems, using introduced CAD. Combination of phases allows to accelerate process of production release, without spending time for detailed system preparation for operation. In such cases the greatest quantity of difficulties and collisions in the HMI appears.

Introduction of new CAD in existing production practice is, in fact, aspect of innovative activity at the enterprise. It is known that there are four groups of factors that prevent innovative activity [3]:

- technical-economic;

- legal;

- organizational and managerial;

- social-psychological.

Especially interesting in this list are the social-psychological factors. As a rule, this includes the following circumstances: the possibility of changing the status of the employee in the organization, the possibility of losing the job due to the introduction of innovations, the restructuring of established ways of activity, violation of behavioral stereotypes, fear of uncertainty, fear of punishment for failure, etc. At the same time, the larger the innovation is, the more people are involved in the innovation process, the more often so-called innovative conflicts occur. Radicality of an innovation increases the probability and severity of such conflicts. Moreover, the more rapid the innovation process is, the more conflicting it is.

Speaking about introduction of innovative CAD in the design organizations, it is worth mentioning experience of company "Metropolis" in which transition from traditional 2Ddesigning to the most advanced tools of $3 \mathrm{D}$, intellectual designing - BIM (Building Information Modeling) has been successfully carried out. The Metropolis company was founded in 2005 and has always tried to use BIM-technologies in production activity. The method of "pilot projects"'" was applied in the work. The essence of the given method consists in transition to introduced innovative CAD gradually, in due course increasing quantity of projects which are developed with use of BIM-technologies.

Since 2017 the basis of design activity became program complex Autodesk Revit. In essence, BIM-modelling represents the process based on use of intellectual 3D-models. Transition from 2D designing to 3D solves a number of the typical problems appearing during working out of the technical documentation for one or another object (building, constructions). It is a question of more effective integration of various engineering communications, possibility to consider object of designing as a whole, as information model. Moreover, thanks to the object-oriented approach BIM-modelling allows to create design elements with typical properties and to project them on all model of object at once [14]. Transfer of BIM-model to the customer is carried out by means of open formats, such as IFC (Industry Foundation Classes) or NWC (Autodesk Navisworks) [17,18].

However, in addition to the obvious benefits of switching to BIM modeling, there are a number of negative factors, which are also worth mentioning:

- costs of purchasing and installing the software;

- costs of increasing the capacity of workstations (if necessary);

- increased risk of errors from outside designers, especially in case of parallel passage of stages "introduction" and "operation" CAD;

- lack / deficiency of regulatory documentation, including design standards in the innovative BIM model environment; 
- conservatism of employees of the company and rejection of transition to innovative methods of work.

According to Oleg Baranov, Deputy General Director of Metropolis, the cost of transition to BIM-technologies was about 20 million rubles, and the transition process itself took about one year [20]. The volume of investment depends on many factors, including the number of employees, age of the organization, etc. According to a technique of "pilot" projects the part of stages is developed with application of new CAD, and other part - traditional methods. Such approach allows to make transition to BIM-technologies less painful.

A key aspect of implementation processes is employee training. Specialized courses for employees were organized in Metropolis company, where employees have the opportunity to learn new software, perform practical tasks under the guidance of an instructor. At the same time, the training program for employees of different structural divisions is formed taking into account their specialization and specifics. Thus, employees mostly receive the competences that they personally will need for their work. In Russia for today there is no uniform approach to teaching BIM-modelling for practicing experts and, in this regard, the design organizations are increasingly resorting to foreign experience. In the countries of the western Europe, the USA and Canada the point of view dominates, according to which studying of BIM-modelling should have multistage character, not contain superfluous theoretical deductions and to be as much as possible approached to practical questions of design work $[4,5,19]$. Moreover, more and more foreign experts are invited to the advanced architecturally-building organizations as the adviser on innovative development of the company. The issues of knowledge transfer in a professional environment at the international level are also quite studied from the point of view of methodology and organization [6-10].

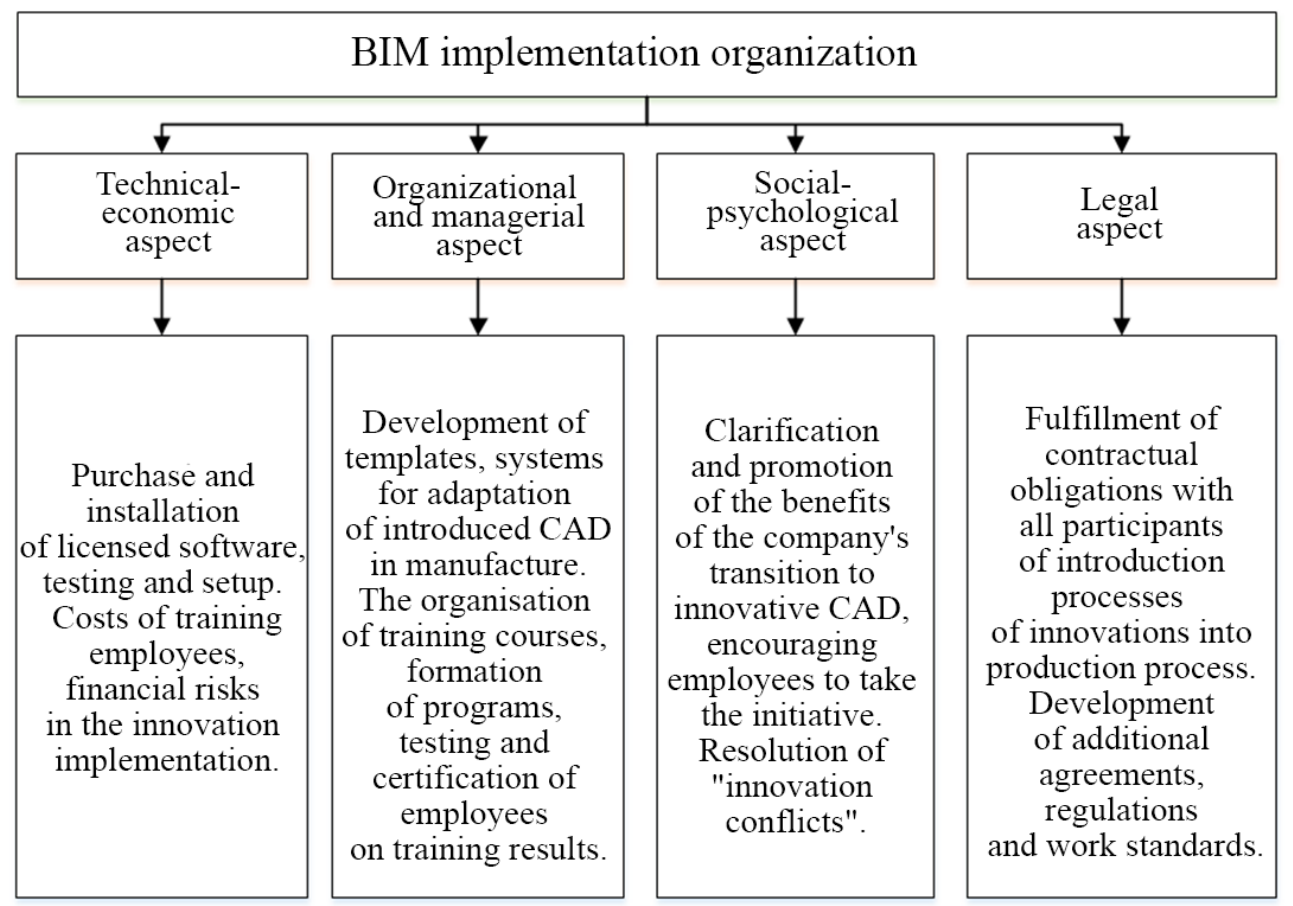

Fig. 2. Organizational activities for implementing innovative CADs (on the example of implementing BIM technologies in Metropolis)/ 
Figure 2 shows the general organization structure of innovative CAD introduction in the design organizations, by an example of introduction of BIM-technologies in the company "Metropolis".

It is impossible to consider the effective organization of introduction of innovative CAD in existing manufacture in isolation from applied aspects of adapting employees of the company to offered innovations. In order to successfully resist possible negative tendencies at CAD introduction, it is necessary to have complex representation about features of interaction of the employee and those hardware and software with which the production of final products is carried out. In this regard it is reasonable to resort to development of the generalized information model of the HMI in the conditions of operation of innovative CAD at "introduction" and "operation" stages. In this case it will be reasonable to unite these two stages in a certain intermediate stage in which process adaptation of the worker to innovative $\mathrm{CAD}$ and release of final production occur in parallel. One of the most convenient ways of information model presentation is a triad infographic model, based on the interaction of three objects (monads) - a person, technology and environment (further PTE) [3, 11]. As objects we accept $\mathrm{CAD}$ operator, workstation with the installed innovative software and environment in which the working process is carried out. We will present information model in the form of a three-point cycle with differently directed influence (figure 3).

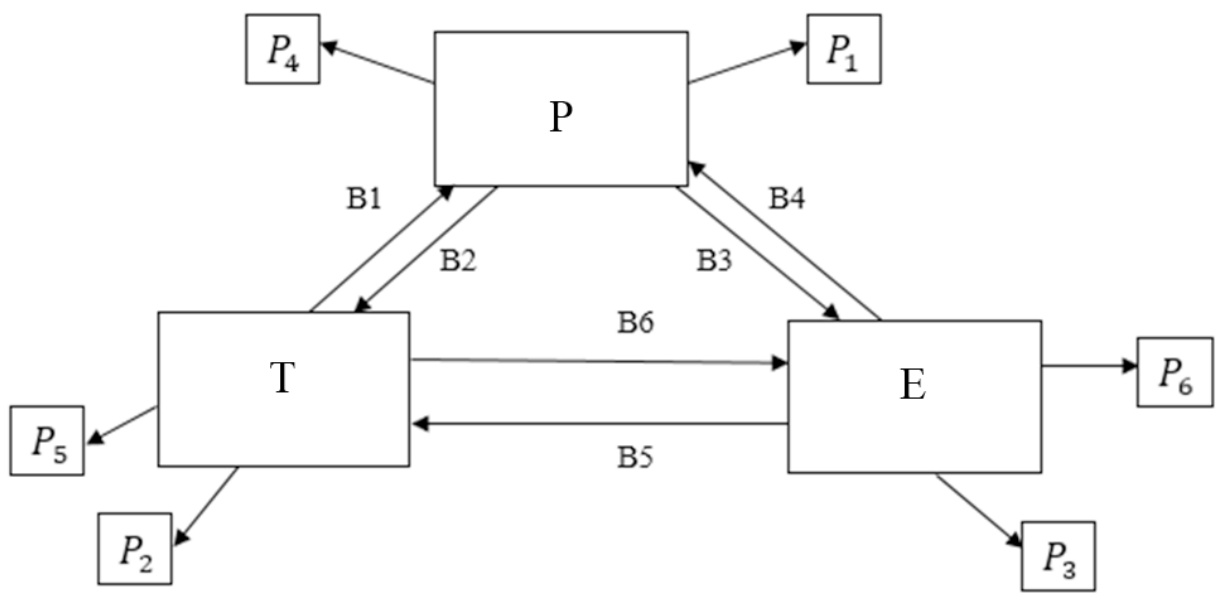

B (1...6) - the components of infographic model influence on each other; $P(1 \ldots 6)$ - results of components of infographic model influence on each other.

Fig. 3. The PTE triad with multi-directional effects.

Let's analyze the influence of model elements on each other (Table 1).

Table 1. Detailed effects of the PTE triad elements

\begin{tabular}{|c|c|}
\hline Number & \multicolumn{1}{c|}{ Description } \\
\hline B1 & $\begin{array}{l}\text { Processing the information entered by the operator. Providing } \\
\text { answers to requests, offering alternatives, informing about errors. } \\
\text { Storage of information. }\end{array}$ \\
\hline B2 & $\begin{array}{l}\text { Entering requests into the system, analysis of received data. } \\
\text { Making decisions that are not available to the system, including in } \\
\text { non-linear conditions. }\end{array}$ \\
\hline B3 & $\begin{array}{c}\text { Creation of completely new products (design documentation). } \\
\text { B4e environment applies any restrictions to the design process } \\
\text { (terms, working conditions, norms, standards and regulations). }\end{array}$ \\
\hline
\end{tabular}




\begin{tabular}{|c|c|}
\hline Number & Description \\
\hline B5 & $\begin{array}{l}\text { Design conditions make certain requirements to the used software } \\
\text { (for example, concerning requirements to availability of } \\
\text { corresponding licenses for the used software). }\end{array}$ \\
\hline B6 & $\begin{array}{l}\text { The conditions are formed taking into account the existing design } \\
\text { systems, which are most widely represented in the market. }\end{array}$ \\
\hline
\end{tabular}

Table 2 shows the analysis results of the model elements' impact on each other.

Table 2. Detailed results of the effects of the PTE triad elements

\begin{tabular}{|c|c|}
\hline Number & \multicolumn{1}{c|}{ Description } \\
\hline P1 & $\begin{array}{c}\text { Implementation of the system request from the designer. The way to } \\
\text { exchange data between man and machine is the CAD interface. The } \\
\text { successfully processed requests forms, eventually, the ready design } \\
\text { document (the drawing, knot, etc.). }\end{array}$ \\
\hline P2 & $\begin{array}{c}\text { The developed solutions that make up the project documentation } \\
\text { become the initial data for the next stages of the production process. }\end{array}$ \\
\hline P3 & $\begin{array}{c}\text { Considering restrictions of the environment, the designer plans the } \\
\text { work, makes some organizational and technical decisions. }\end{array}$ \\
\hline P4 & $\begin{array}{l}\text { Demand caused by many factors sets forth the requirements and } \\
\text { standards to which CAD must comply. Under the influence of these } \\
\text { factors, existing systems are being modernized and updated. }\end{array}$ \\
\hline P6 & $\begin{array}{l}\text { Features of various software components, which are really widely } \\
\text { represented on the market, become an important factor for customers. } \\
\text { Specification, generally, takes into account the capabilities of the } \\
\text { software environment in which the system is developed. }\end{array}$ \\
\hline
\end{tabular}

\section{Results}

The used system analysis technique can have much more detailed study. Thus, the quantity of the processes proceeding in the course of interaction of the worker and CAD can be essentially increased. However, by results of the spent research, even within the limits of the set scalability, we have possibility to make some conclusions:

1. The essence of operator-system interaction is the exchange of information. In this case the user enters a request in the system, and as a feedback receives a system response to this request.

2. The completed design document (the drawing, the scheme, assembly, etc.) is formed during implementation of many successfully processed by system requests.

3. The communication center is the interface of an automated system. This means that effective interaction in this case is directly proportional to the level of user interface ergonomics, taking into account the specifics of the individual employee.

4. Organizational factors of the exterior, such as working conditions, deadlines for solving tasks, should take into account real possibilities of the operator in the specified working conditions.

5. It is necessary to free the employee from solving routine, easily formalizable tasks and transfer these functions to automated data processing systems. The operator should focus his attention on solving nontrivial, nonlinear problems, in which the solution can not be picked up by a formalized algorithmic scenario. 
6. The transition to the new project platform is better done gradually using the "pilot projects" method. This will make the transition process less painful.

\section{Conclusion}

Understanding the features of interaction between the designer and CAD is the most important element of effective organizational and managerial decisions, when introduced innovative technologies in the design. It is necessary to consider all most significant aspects of implementation, including undetermined events or "the human factor". Persons at the enterprise responsible for implementation of innovation, personnel management and the production organization should not disregard individual features of employees during implementation of innovative technologies in the company. It is necessary to create road maps, imitation models of innovative CAD introduction in production system. In a case when the company does not have qualified experts in change management, heads of the enterprises address in consulting agencies which on a contractual basis carry out complex intellectual support for the implementation of innovations. System work in this direction will allow to realize transition to more advanced, innovative $\mathrm{CAD}$ much more effectively.

\section{References}

1. Fisun A. P., Graschenko LA and others. Theoretical and practical bases of the mancomputer interaction: basic concepts of the man-computer systems in informatics and information security (in Russian) / A.P. Fisun. Deep. in VINITI 15.10. 2004 № 1624 - V 2004. Orel: Orel State University, 2004. 169 p.

2. Rudinskiy I.D. Design technology of the automated systems of information processing and management: Training manual for higher educational institutions. Moscow: Gor. line - Telecom, 2011. 304 p.

3. Chulkov V.O. Infographics. Volume 1: Multilevel infographic modeling. Modular lecture course. Infographics basics of the functional systems" series. (IOFS) Moscow: SvRARGUS, 2007. 352p.

4. Abdirad H., Dossick C.S. (2016). BIM curriculum design in architecture, engineering, and construction education: a systematic review. // Journal of Information Technology in Construction (ITcon), Vol. 21, pg. 250-271.

5. Barison, M. and Santos, E. (2011) BIM Teaching: Current International Trends. // Gestão \& Tecnologia de Projetos, 6(2), pp.67-80.

6. Murray A.J. International Personnel Repatriation: Cultural Shock in Reverse. 1973, vol. 21 (3), pg. 59-66.

7. Howard C.G. The returning overseas executive: Cultural Shock in Reverse. Human Resource Management, 1974, vol. 13 (2), pp. 22-26.

8. Rohr U. Factors Influencing Repatriate Knowledge Management. 2006, № 6.

9. Szulanski G. Exploring Internal Stickiness: Impediments to the Transfer of Best Practice within the Firm. Strategic Management Journal, 1996, 17 (Winter Special Issue), p. 27 43.

10. Dadonov V.A., Ruler I.A. Analysis of the factors influencing on management and knowledge transfer of the international employees in the company. "Engineering Journal: Science and Innovations", 2014, issue № 7

11. Vannusov D.D. Information modelling of energy-efficient technologies in investmentconstruction activity. Scientific-practical problems and directions of their solution in the field of high technologies [Text]: collection of articles of the International scientificpractical conference, 2017 : [in 2 p.] /2017. Pg. 20-22. 
12. Namiot, D. On Big Data Stream Processing / D.Namiot // International Journal of Open Information Technologies. - 2015. - Vol. 3. - №8. - pp. 48-51.

13. Franconi, E. Ontologies and Databases: myths and challenges / E. Feanconi // VLDB Endowment, ACM, - 2008. - pp. 1518-1519.

14. Eastman, C., Teicholz, P., Sacks, R., Listo, K. (2011). BIM Handbook: A Guide to Building Information Modelling for Owners, Managers, Designers, Engineers and Contractors. Hoboken: Wiley Johns \& Sons.

\section{GOST, OST, GTM:}

15. GOST 34.003-90 Automated systems. Terms and Definitions. [Electronic resource] // URL: http://docs.cntd.ru/document/gost-34-003-90 (accessed: 11/25/2019))

16. GOST 23501.101-87 Computer-aided design systems. Key points [Electronic resource] // URL: http://docs.cntd.ru/document/1200012840 (date of access: 11.25.2019)

17. Code of Practice 328.1325800.2017 Information modeling in construction. Rules for the description of the components of the information model. [Electronic resource] // URL: http: // http://docs.cntd.ru/document/556793891 (accessed date: 01/19/2020)

18. Code of Practice 331.1325800.2017 Information modeling in construction. Rules for the exchange between information models of objects and models used in software systems. [Electronic resource] // URL: http: //docs.cntd.ru/document/556793894 (date of access: $01 / 19 / 2020)$

\section{Digital media:}

19. Bozoglu J. (2016) Collaboration and coordination learning modules for BIM education. // Journal of Information Technology in Construction (ITcon), Special issue: 9th AiC BIM Academic Symposium \& Job Task Analysis Review Conference, Vol. 21, pg. 152163. [Electronic resource]. - Access mode: http://www.itcon.org/2016/10 (02.01.2017)

20. Upcoming digitalization - Komersant St. Petersburg [Electronic resource] // URL: https://www.kommersant.ru/doc/4052322. (date of access: 11/25/2019)

21. Drogovoz, P.A.; Leus, N.A. World tendencies of development of the predictive analysis of the big data in the industrial sphere (in Russian) // Economics and business. 2019. № 4. Pg. 168-176.

22. Falko, S.G. Cyberrisky and digital economy// Management innovations. 2019. № 3 (21). Pg. 2-3 